\title{
Colectivo El Marrano de Barro. Artista invitado
}

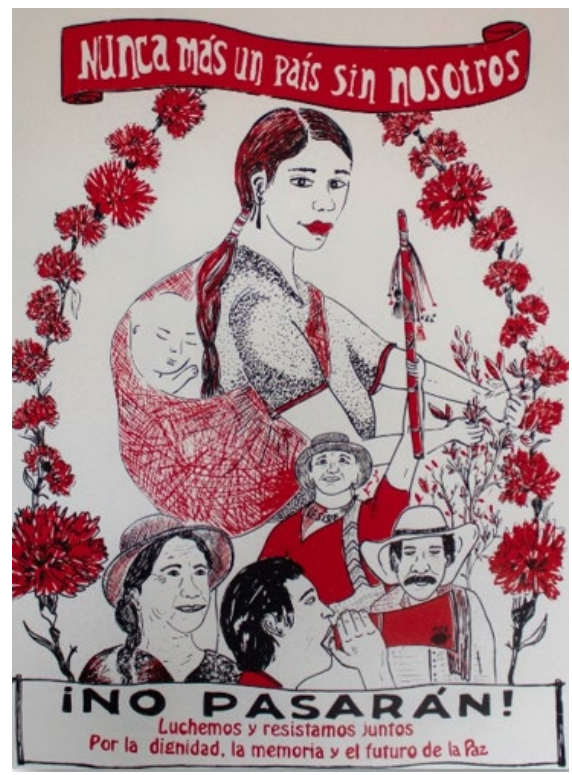

Nunca Más

Mabel Novoa y Taira Rueda, dos artistas visuales recién egresadas de la Pontificia Universidad Javeriana de Bogotá, Colombia en 2013, se unieron para crear un colectivo independiente. Por la limitada situación económica, los ahorros fueron la principal fuente de financiación y llamaron al proyecto Marrano de barro, en analogía con la cerámica que simboliza la economía popular en el país (Palacio, 2020). En el 2016 Pablo Correa se integró al colectivo.

Este colectivo gráfico y audiovisual se ha enfocado en la paz, como un compromiso fundamental en la construcción de país, con el fin de visibilizar experiencias de resistencia, desde procesos de construcción de memoria. Ha impreso carteles para manifestaciones, desarrollado jornadas de estampado serigráfico en espacios públicos; ha realizado crónicas audiovisuales, cortos en animación, trabajo con comunidades campesinas sobre problemáticas sociales y políticas. También ha participado en las redes sociales con la producción gráfica de "Cartelismo digital" sobre coyunturas sociales y ha ayudado a visibilizar, desde el arte, diversas dinámicas y procesos sociales (Colectivo Marrano de Barro, 2020).

(i)(2) Esta obra está bajo una Licencia Creative Commons Atribución-NoComercial-CompartirIgual 4.0 Internacional.

\section{¿Cómo citar este artículo? / How to quote this article?}

Prospectiva. (2021). Colectivo El Marrano de Barro. Artista invitado. Prospectiva. Revista de Trabajo Social e intervención social, (31), 479-488. doi: 10.25100/ prts.v0i31.10890. 
Prospectiva

El colectivo asume la serigrafía como forma de expresión artística, técnica rústica de impresión de documentos e imágenes, que se puede realizar en diversos entornos y permite muchas reproducciones de una imagen en un corto periodo de tiempo, su realización es económica y casera.

Desde el cartel político, ligado a la serigrafía y talleres de grabado, el Marrano de Barro comenzó a participar en protestas, se articuló al movimiento social, empezó a salir a las calles a regalar carteles que elaboraban en su taller. Así, usó la gráfica y el cartelismo como instrumento de comunicación popular y masiva, al reconocer el poder de la imagen para la transmisión de ideales de cambio.

En el contexto del Plebiscito por la paz en el 2016, Taira, Mabel y Pablo, orientaron sus trabajos a motivar a votar por el Sí. A partir de ahí y de la derrota, fueron a los Llanos del Yari y participaron en la vigilia por la paz que hizo las FARC al sur de la Serranía de la Macarena en las Sabanas que otrora fueron uno de los escenarios más importantes del conflicto armado; allí realizaron videos y jornadas de estampado, ratificando el compromiso político de reivindicar luchas con la clase trabajadora y las comunidades olvidadas.

Pablo y Taira trabajaron con la Asociación Campesina del Valle del Río Cimitarra, ACVC, haciendo videos para comunidades campesinas. Integraron un trabajo comunitario en campo y la propuesta política en las calles a partir del cartel, participando en las protestas de noviembre de 2019 y de 2020.

En el 2020 el colectivo empezó a cosechar la incidencia del intercambio de saberes en la producción artística: ganó la beca de técnicas no digitales para cartel del Ministerio de Cultura, fruto de la cual desarrollaron la exposición de 12 afiches impresos en serigrafía, en homenaje a manifestaciones, marchas, plantones y huelgas en Colombia en el último siglo, para des-estigmatizar la protesta social e invitar a reflexionar y aprender de las fuerzas organizativas del pasado por la conquista de derechos en el futuro (60 horas de impresión, 3750 impresiones, 1800 afiches). Así reivindican la movilización de los pueblos en Colombia, como homenaje a quienes han luchado en nuestra compleja y combativa historia.

También desarrollaron la recopilación de cuatro historias colombianas de resistencia desde el territorio que publicaron en una colección de 4 Fanzines $^{1}$ : “1. Y aquí seguimos:

1 La palabra Fanzine proviene de la abreviatura en ingles de Fan's y Magazine, es decir, revista de fanáticos. Es interesante su carácter flexible en relación con los cánones y géneros literarios y periodísticos. En él se pueden combinar y acoplar técnicas que ofrecen distintos géneros, lo que convierte al fanzine en una herramienta comunicativa hibrida y creativa, que permite explorar formas alternativas de comunicar: además de lo escrito, se desarrolla de manera importante, lo visual, comprendiendo las fotografías, dibujos, infografías, recortes de prensa etc., además de la creatividad colectiva que se plasma en las texturas, materiales y extensión que se le quiera dar (Thomas, Rubio y Muñoz, 2018). 
Prospectiva

resistencia campesina en Puerto Nuevo Ite"; “2. Hagamos algo esta noche: Martha, resistiendo al olvido"; "3. El remanso: resistiendo a la guerra que el río trajo a Beltrán”; “4. La Madre Cindy: construyendo el hogar, resistiendo desde el cuerpo". Todas, fruto de la beca para proyectos editoriales independientes en artes plásticas, categoría publicaciones seriadas, periódicas o fanzine (Alcaldía Mayor de Bogotá, Instituto Distrital de las artes).

En el 2020 Pablo y Taira realizaron El Marranito Animado, serie de 4 videos publicada en youtube en el confinamiento por la pandemia del Covid 19, como aporte didáctico para aprender animación, para adultos, niños, niñas y estudiantes, que no sabían en qué usar el tiempo libre:

- $\quad$ https://www.youtube.com/watch?v=CD3Xr1a9faw

- $\quad$ https://www.youtube.com/watch?v=ri4hA6BaXoA

- https://www.youtube.com/watch?v=VF29TIMEFeo

- https://www.youtube.com/watch?v=SwyO46sHOoM

Los colectivos se crean como expresiones sociales de un tiempo histórico y condiciones sociales; en el Marrano de Barro, un interés común ha sido visualizar como importante forma de poder social, la orientación cultural de nuevos movimientos sociales, como una forma de resistencia (Rodríguez-Pizarro,2005).

El colectivo también ha participado en:

\section{Proyectos editoriales independientes}

- Reglas de comportamiento en combate, editado por El Comité Internacional de la Equis Roja en 2013.

- Libro Contable, editado por el colectivo Amapola Cartonera en 2014.

\section{Exposiciones colectivas}

- V Bienal de Egresados de la Carrera de Artes Visuales PUJ. Sala de exposiciones Santiago Páramo. 2014

- Habitar ser y sentir las fronteras. Cámara de Comercio de Bogotá, 2017.

- Contra/Anti/Pos/Des/De-Colón-Bianidad. Desborde Galería. 2020. 
Prospectiva

\section{Acompañamiento desde el Arte a comunidades en sus procesos de resistencia}

- $\quad$ Laboratorios de creación en Inírida con el Ministerio de Cultura, 2013, 2014, 2015: historias del Guainía.

- Apoyo a organizaciones desde la gráfica y la diagramación: cumbre agraria, campesina, étnica y popular, agenda común de paz.

- Memorias campesinas y protección de derechos para la paz, Asociación Campesina del Valle del Río Cimitarra, 2017-2018.

- Talleres de sensibilización sobre la IVE “Intervención Voluntaria del Embarazo” con realización de un mural y registro audiovisual de su creación. Fundación Sí Mujer, Bogotá. 2017.

- Jornadas de Estampado: contra la destrucción de la Reserva Van Der Hammen. Plaza de Bolívar, Bogotá. 2017. Por la paz. Bogotá. 2018. Festival Codito de Colores. Barrio El Codito, Bogotá. 2019.

- Registro de Jornada de Salud en el Espacio Territorial de Capacitación y Reincorporación ETCR Mariana Páez, Granada, Meta. 2017.

- Talleres de construcción de memoria histórica.

- Festival Ojo al Sancocho.

- $\quad$ Novena política 2018

- Jornada de impresión para el festival Codito de Colores 2019

- Talleres con niños y niñas de la vereda, Beltrán Risaralda

- Marchas: Plantón frente al Ministerio del Medio Ambiente, 2019. Por los líderes sociales, 2019, manifestaciones 2020.

\section{Referencias bibliográficas}

Colectivo Marrano de Barro (2020). Reseñas y documentos. Manuscrito inédito.

Palacio, S. (2 de diciembre de 2020). Sección Cultural. Periódico Vox.

Rodríguez-Pizarro, A. N. (2005). Panorama teórico: acción colectiva, movimientos sociales e interseccionalidad con la perspectiva de género. En Rodríguez-Pizarro, A. N. (Comp.), Sujetos sociales, acciones colectivas y Trabajo Social. Cali, Colombia: Universidad del Valle. Escuela de Trabajo Social y Desarrollo Humano.

Thomas, J., Rubio, J., y Muñoz, I. (2018). El Fanzine y la comunicación del riesgo: una propuesta para el Valle del Cauca, Colombia. REDER, 2(1), pp.53-70. Recuperado de http://www.revistareder.com/ojs/index.php/reder/article/view/11.

Datos sobre redes sociales: Correo electrónico: elmarranodebarro@gmail.com @MarranoDeBarro en Instagram y Facebook Whats app + 57 3013391565. +57315 4475390 
Prospectiva

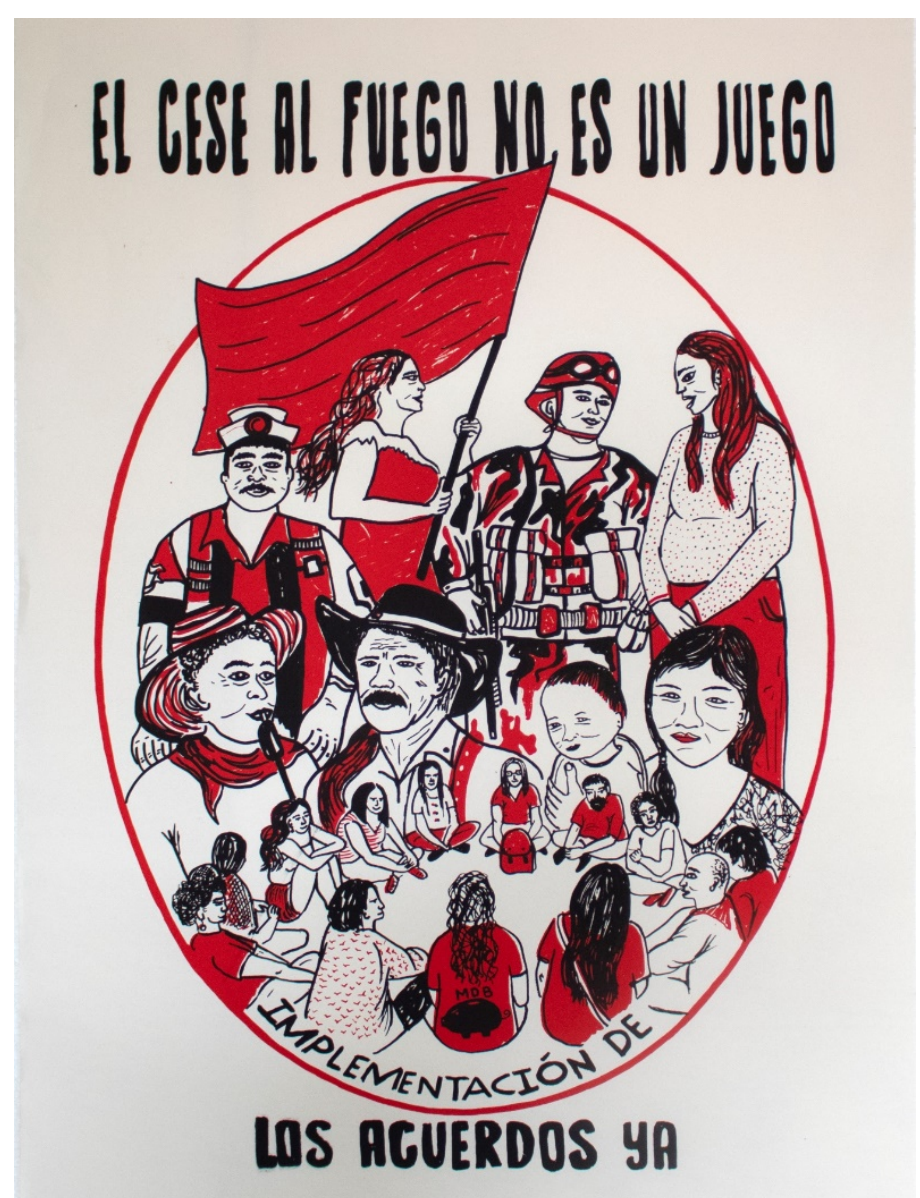

Cese

Colectivo El Marrano de Barro

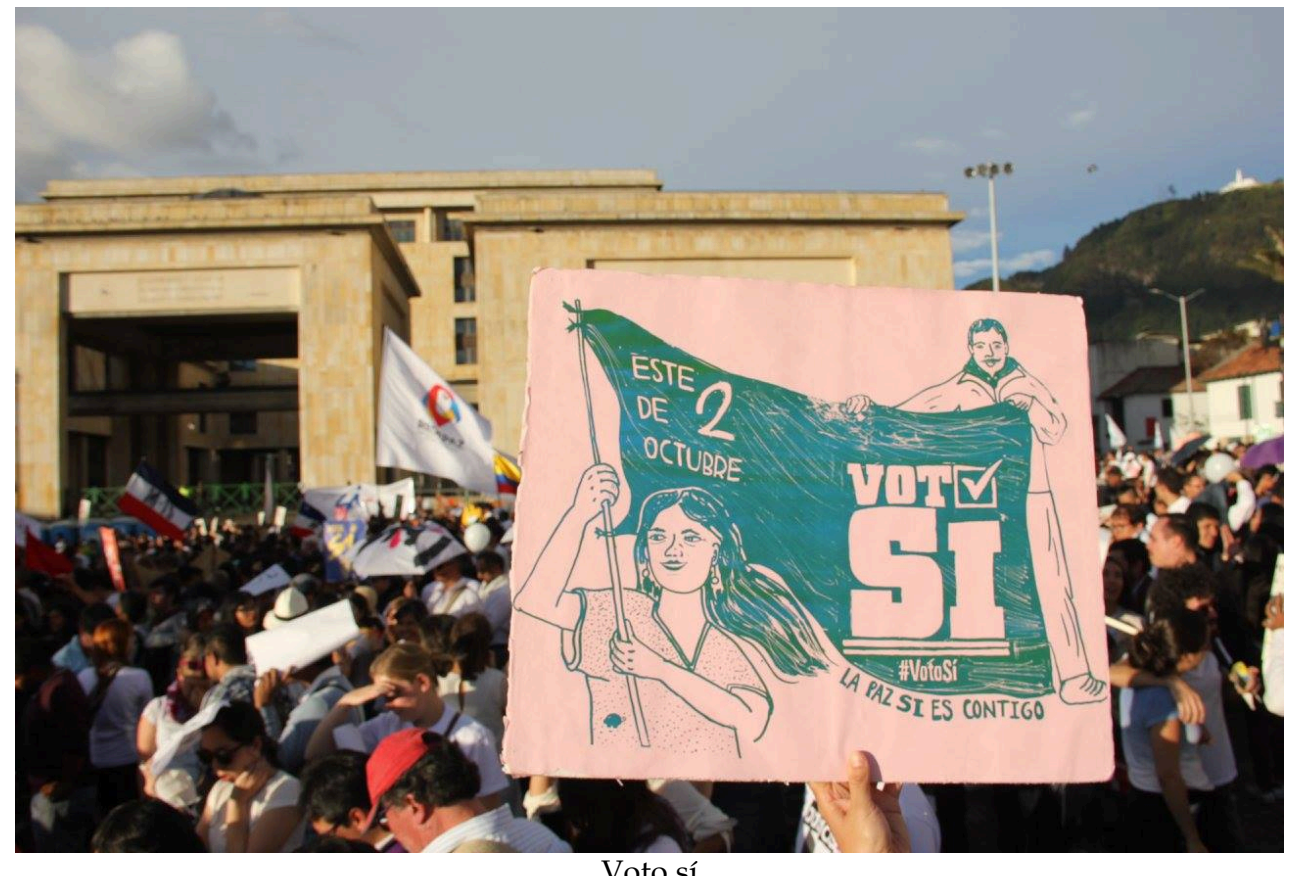

Colectivo El Marrano de Barro 


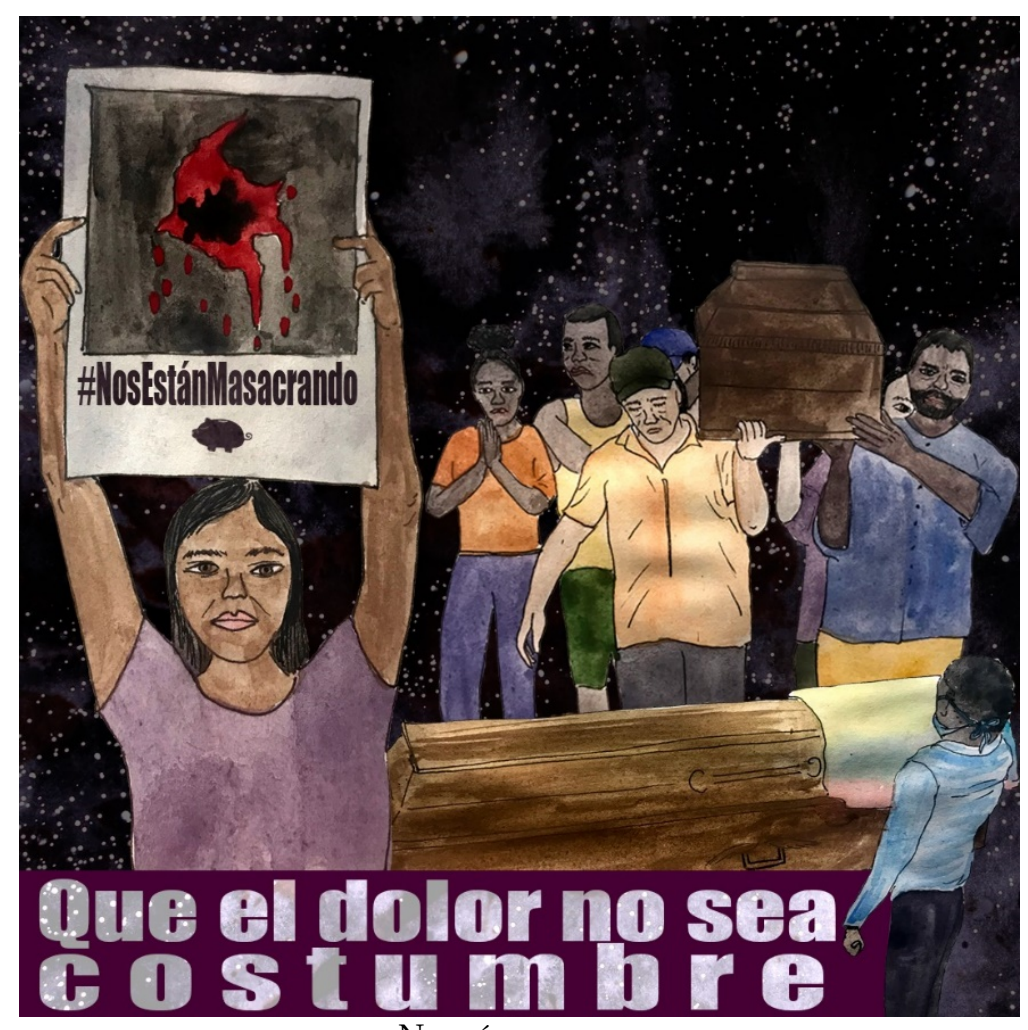

No más masacres

Colectivo El Marrano de Barro

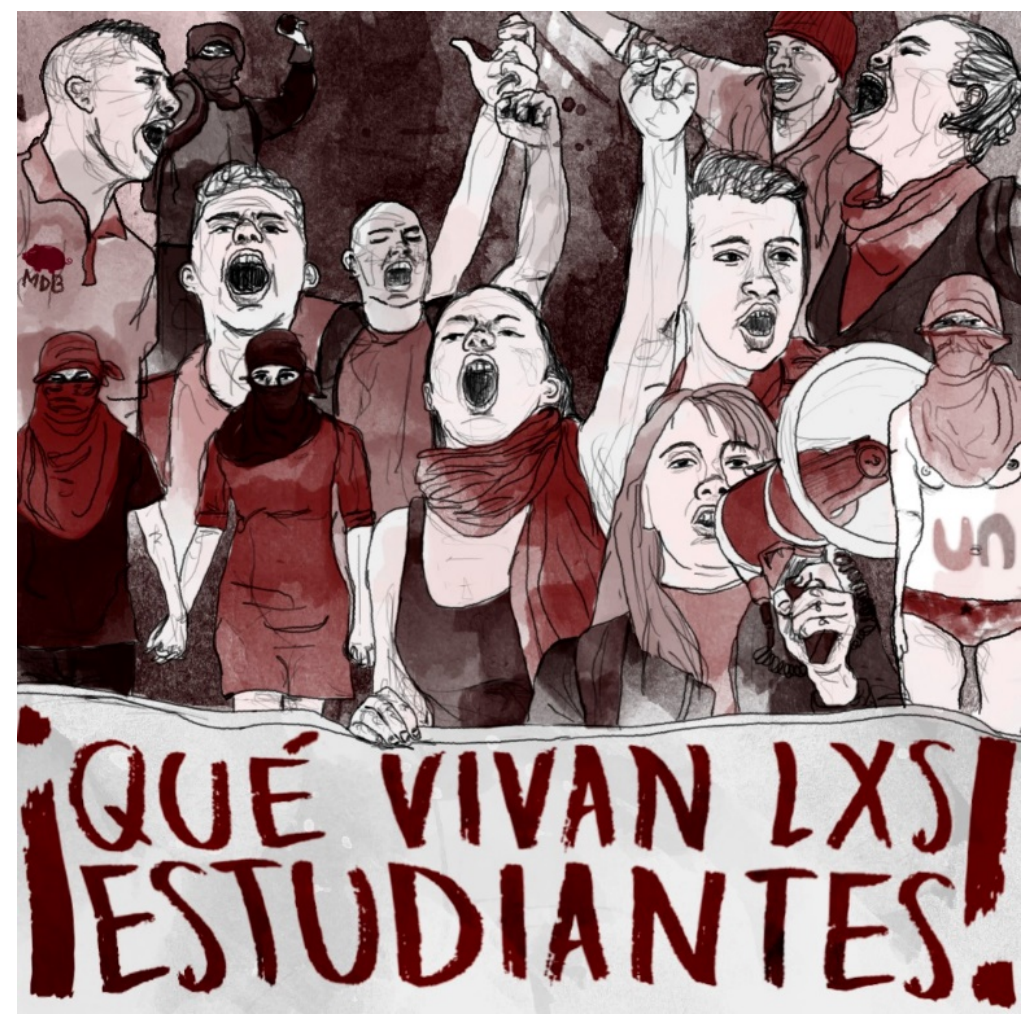

Estudiantes

Colectivo El Marrano de Barro 
Prospectiva

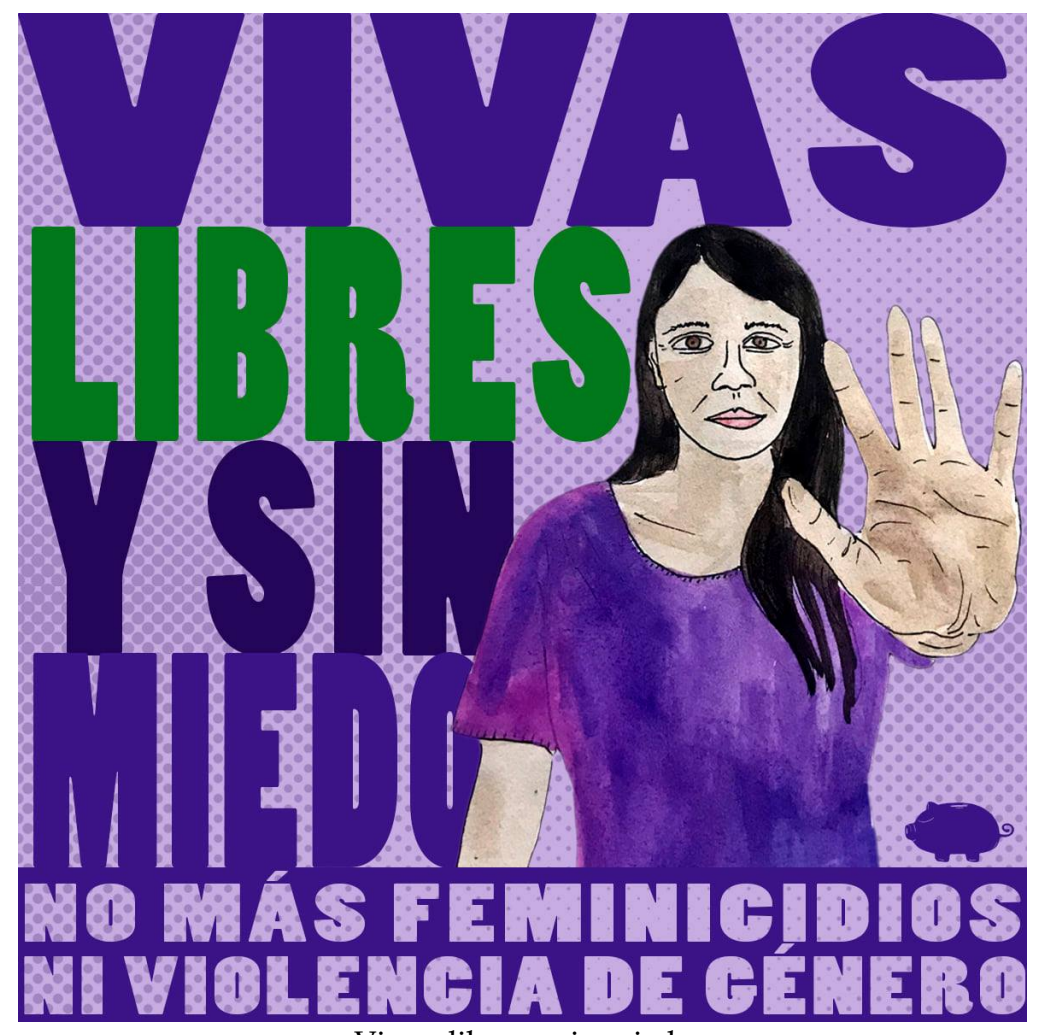

Vivas, libres y sin miedo

Colectivo El Marrano de Barro

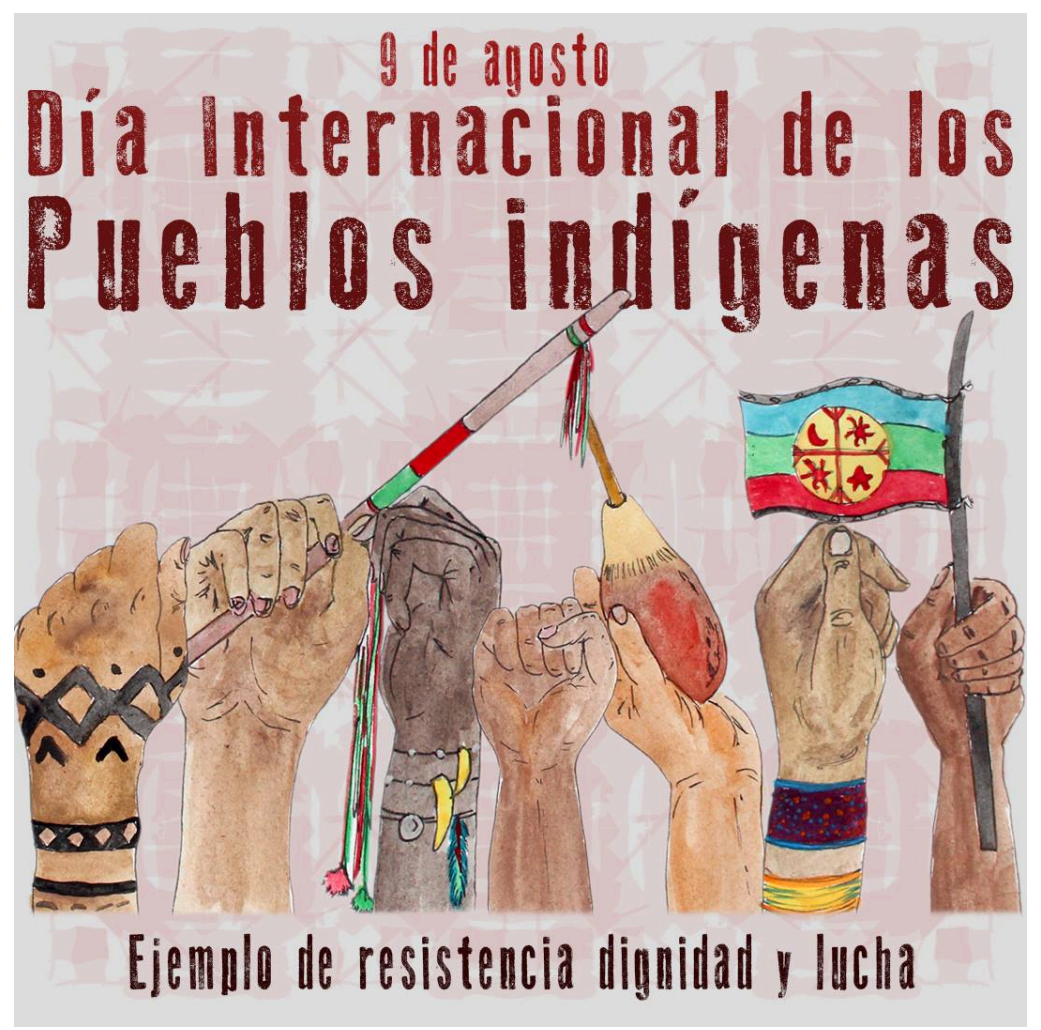

Pueblos indígenas

Colectivo El Marrano de Barro 
Prospectiva

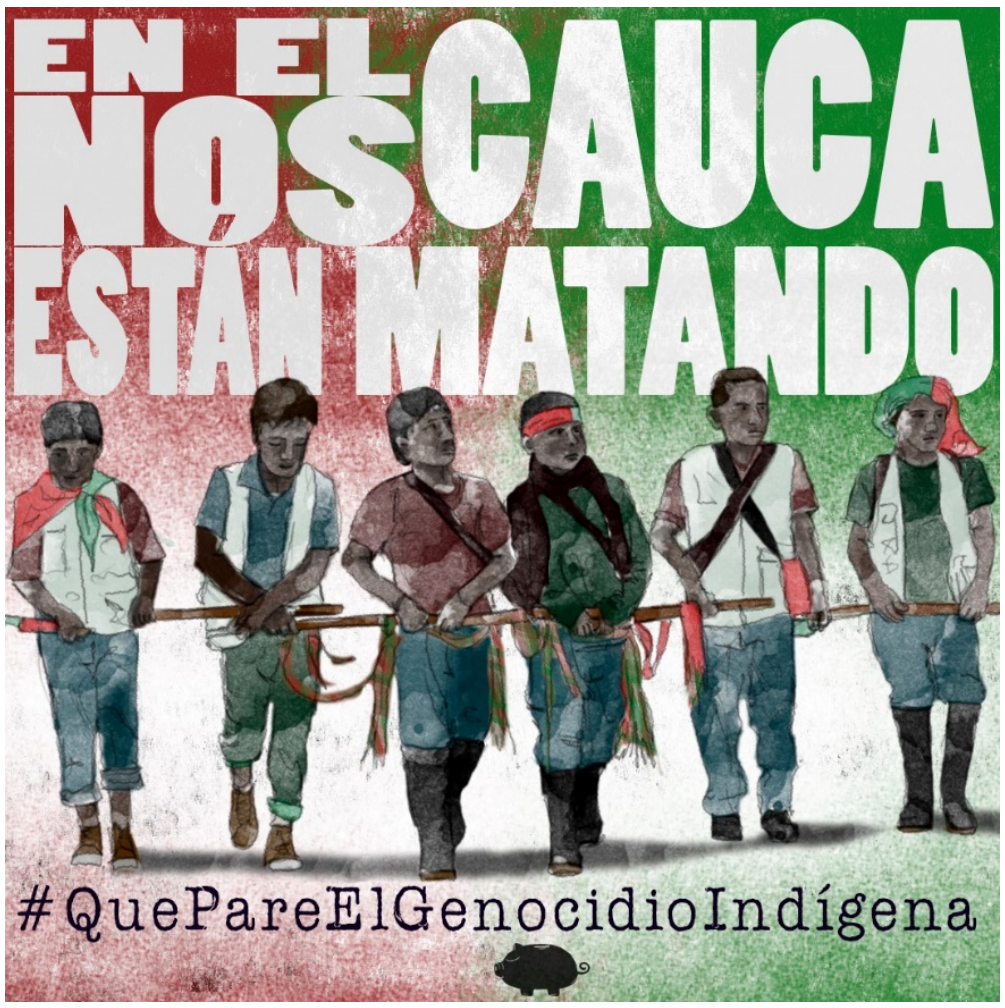

Genocidio

Colectivo El Marrano de Barro
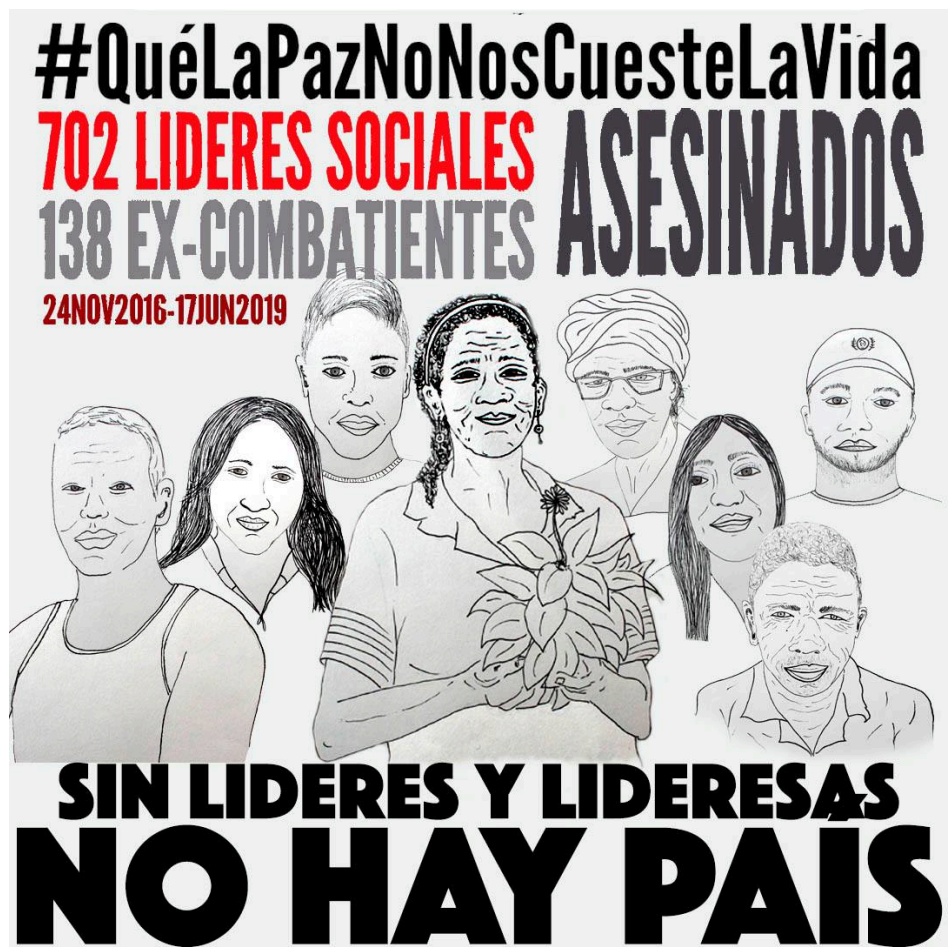

Lideres

Colectivo El Marrano de Barro 
Prospectiva

\section{LOS LÍDERES SOCLALS LUCHAN POR NUESTROS DERECHOS}
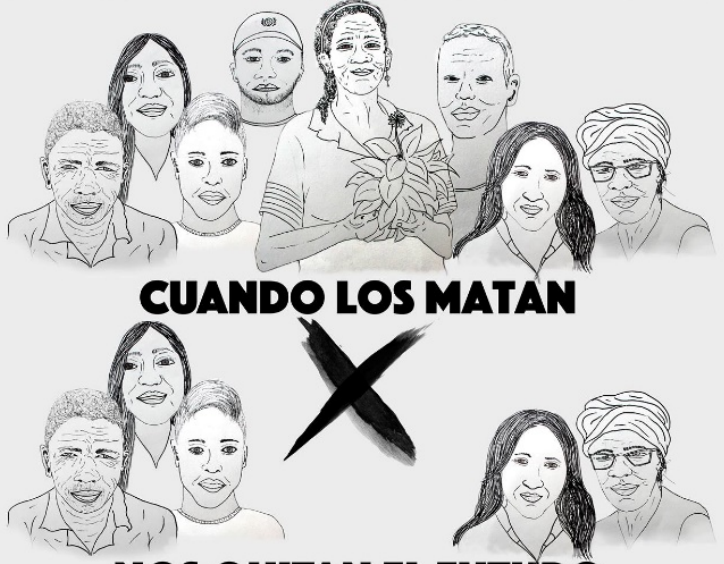

NOS OUITAN EL FUTURO

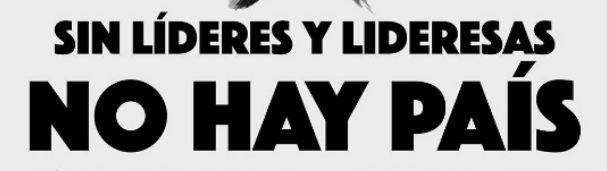

467 LIDERESAS Y LÍDERES HAN SIDO ASESINADOS DESDE LA FIRMA DE LOS ACUERDOS DE PAZ Líderes, homenaje

Colectivo El Marrano de Barro

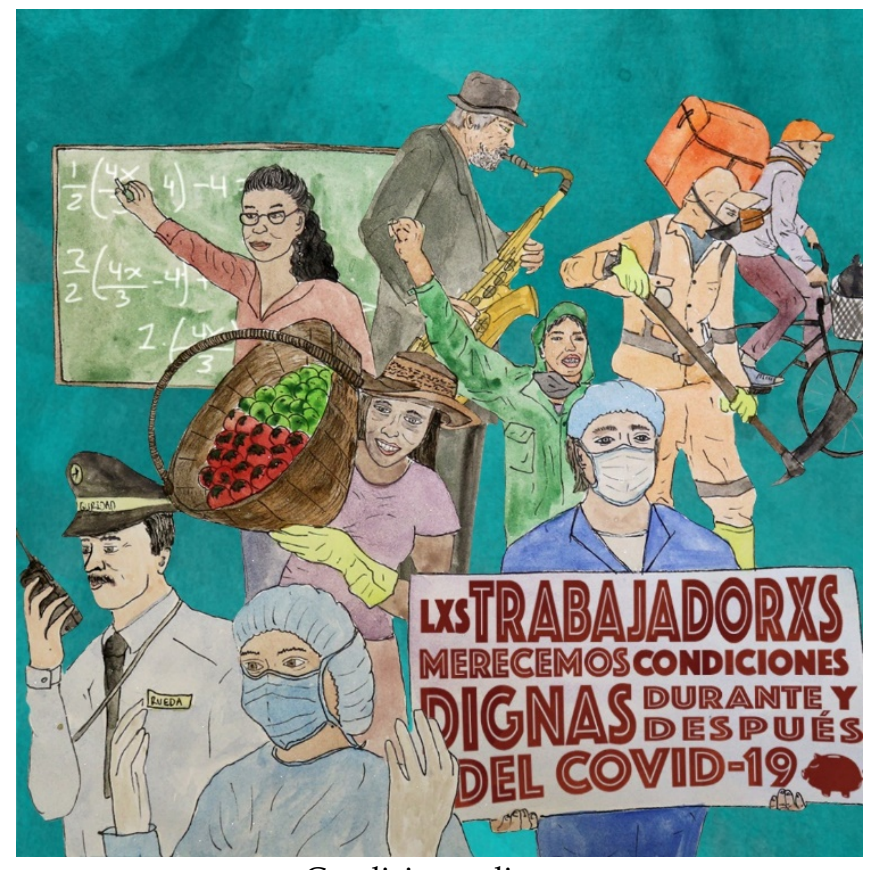

Condiciones dignas

Colectivo El Marrano de Barro 
Prospectiva

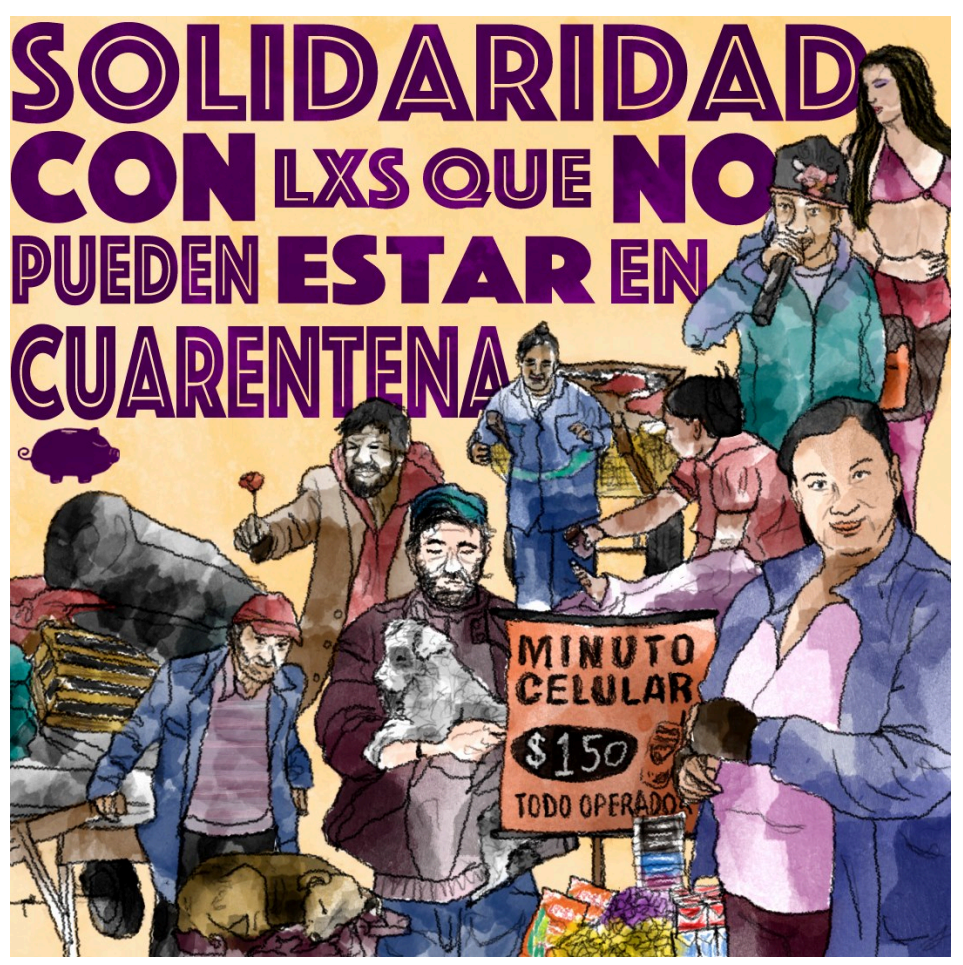

Solidaridad

Colectivo El Marrano de Barro 